\title{
Giant right atrium with severe pulmonary hypertension
}

\author{
Theodoros Kelesidis MD, Michael Maysky MD, Iosif Kelesidis MD
}

A n 84-year-old woman with a history of atrial fibrillation presented with cough, lethargy and symptoms of progressive heart failure. She had not seen a physician for many years, despite persistent symptoms. Physical examination showed an elevated jugular venous pressure, a grade $2 / 6$ holosystolic murmur at the left sternal border and apex, hepatomegaly and severe edema in her legs.

Chest radiography indicated marked cardiomegaly. A computed tomography scan with intravenous contrast showed marked enlargement of the right atrium, which almost filled the chest cavity (Figure 1A). An echocardiogram revealed massive enlargement of the right atrium, a normal-sized left atrium, mild dilatation of the right ventricle, and moderate mitral and severe tricuspid regurgitation (Figure 1B). Left ventricular size and function were normal. The right atrium measured $11 \times 12 \mathrm{~cm}$ and had a calculated volume of 760 (normal 20-40) $\mathrm{mL}$ - representing one of the largest right atria described in an adult. ${ }^{1}$ Systolic pulmonary artery pressure was 90 (normal < 40) $\mathrm{mm} \mathrm{Hg}$, consistent with severe pulmonary hypertension. The patient was discharged home with oxygen and diuretics, but she had a cardiac arrest four weeks later and died.

Massive enlargement of the right atrium is usually associated with congenital heart disease in infants and children. ${ }^{2,3}$ We found only two reports of a giant right atrium in adults. ${ }^{1,4}$

The most common causes of an enlarged right atrium in adults are chronic pulmonary disease, severe mitral valvular abnormalities with pulmonary hypertension, pulmonary emboli and tricuspid valvular stenosis. ${ }^{1}$ Few studies have evaluated the velocity of dilatation of the right chambers in humans. ${ }^{5}$ In a prospective study, Cioffi and colleagues found that right atrial size, systolic function and wall stress increase

From the departments of Medicine (Theodoros Kelesidis) and Cardiology (Maysky), Caritas St. Elizabeth's Medical Center, Tufts University School of Medicine, Boston, USA; and the Department of Cardiology (Iosif Kelesidis), Montefiore Medical Center, Albert Einstein School of Medicine, New York, USA

CMAJ 2010. DOI:10.1503/cmaj.090671 substantially in pulmonary hypertension, and activation of the Frank-Starling mechanism occurs in both right chambers. ${ }^{6}$ Interestingly, our patient had only mild dilatation of the right ventricle, and we believe that severe tricuspid regurgitation most likely caused the disporportionate dilatation of the right atrium.

This article has been peer reviewed.

Competing interests: None declared.

\section{REFERENCES}

1. Ariyarajah V, Soni A, Morris A. Giant right atrium in an adult. Echocardiography 2008;25:1121-3.

2. De MS, Bollero E. [Isolated right atriomegaly.] Boll Soc Ital Cardiol 1967;12:16-22.

3. Saigusa M, Morimoto K, Koike T, et al. Idiopathic enlargement of the right atrium. Jpn Heart J 1962;3:373-9.

4. Hager S, Mahrholdt H, Goldfarb LG, et al. Images in cardiovascular medicine. Giant right atrium in the setting of desmin-related restrictive cardiomyopathy. Circulation 2006;113:e53-5.

5. Kurz DJ, Oechslin EN, Kobza R, et al. Idiopathic enlargement of the right atrium: 23 year follow up of a familial cluster and their unaffected relatives. Heart 2004;90:1310-4.

6. Cioffi G. de Simone G, Mureddu G, et al. Right atrial size and function in patients with pulmonary hypertension associated with disorders of respiratory system or hypoxemia. Eur J Echocardiogr 2007;8:322-31. 